Check for updates

Cite this: RSC Adv., 2019, 9, 17501

Received 2nd April 2019

Accepted 28th May 2019

DOI: $10.1039 / c 9 r a 02473 e$

rsc.li/rsc-advances

\section{Consumption of post-fermented Jing-Wei Fuzhuan brick tea alleviates liver dysfunction and intestinal microbiota dysbiosis in high fructose diet-fed mice}

\begin{abstract}
Xiangnan Zhang, ${ }^{a}$ Qiu Wu, ${ }^{a}$ Yan Zhao, ${ }^{\text {b }}$ Alim Aimy ${ }^{\mathrm{a}}$ and Xingbin Yang (iD *a
Emerging evidence supports the health-promoting ability of a special microbial-fermented Fuzhuan brick tea. Epigallocatechin gallate was identified as a dominant flavonoid of Fuzhuan tea aqueous extract (FTE). Mice were treated with $30 \%$ high fructose (HF) water feeding alone or in combination with administration of FTE at $400 \mathrm{mg}$ per $\mathrm{kg}$ bw for 13 weeks. FTE caused strong inhibition against the elevation of liver weight, serum enzymatic (aspartate aminotransferase, aspartate aminotransferase and alkaline phosphatase) activities and hepatic inflammatory cytokines (interleukin-1, interleukin-6, tumor necrosis factor $-\alpha$ and tumor necrosis factor- $\beta$ ) formation, as well as dyslipidemia (total cholesterol, total triglyceride, low-density lipoprotein-cholesterol and high-density lipoprotein-cholesterol) in HF-fed mice $(p<0.05)$. Hepatic malonaldehyde formation was lowered, while superoxide dismutase and glutathione peroxidase activities were enhanced by FTE treatment, relative to HF-fed mice $(p<0.05)$, and histopathological evaluation confirmed the protection. As revealed by $16 \mathrm{~S}$ rDNA gene sequencing, FTE notably increased abundance of Bacteroidetes and Lactobacillus, but reduced population of Firmicutes, Proteobacteria and Tenericutes in HF feeding mice. These findings suggest that FTE exerts a hepatoprotective effect by modifying hepatic oxidative stress, inflammatory response and gut microbiota dysfunction.
\end{abstract}

\section{Introduction}

Fructose is a kind of food ingredient which has been widely consumed in recent years, and high-fructose (HF) corn syrup has been used as a sweetener substitute for glucose and sucrose since the 1990s. ${ }^{1,2}$ As consumption of an HF diet (HFD) is increasing year by year, it has emerged as one of the risks contributing to the epidemic of many chronic diseases, including liver injury.,4 More and more epidemiological and clinical experimental studies and animal studies have proved that HFD can cause an increase in body weight, hepatic fat accumulation and hepatocellular antioxidant defence disorders., ${ }^{5,6}$ More seriously, excessive fructose intake results in intestinal microbiota disorder, which is an early sign of nonalcoholic fatty liver diseases (NAFLD) with a variety of consequences including metabolic disorders and diabetes. ${ }^{7-9}$ Therefore, it has been urgent to find the effective, healthy and natural

\footnotetext{
${ }^{a}$ Shaanxi Engineering Laboratory for Food Green Processing and Safety Control, Shaanxi Key Laboratory for Hazard Factors Assessment in Processing and Storage of Agricultural Products, College of Food Engineering and Nutritional Science, Shaanxi Normal University, Xi'an 710119, China. E-mail: xbyang@snnu.edu.cn; Fax: +86-2985310517; Tel: +86-29-85310580

${ }^{b}$ Key Laboratory of Ministry of Education for Medicinal Resource and Natural Pharmaceutical Chemistry, College of Life Sciences, Shaanxi Normal University, Xi'an 710119, China
}

food ingredients for therapeutic and prevention against HFDinduced liver injury and gut microbiota dysbiosis.

Emerging evidence supports the health-promoting benefits of many post-fermented Chinese brick tea. ${ }^{10}$ Fuzhuan tea is a unique post-fermented product by deliberate fermentation with probiotics Eurotium cristatum as a dominant fungus, which is commonly known as "golden flower", distinguished from the other post-fermented teas. ${ }^{11}$ During the northern song dynasty (1068-1077 AD) in ancient China, the term of "Fu Tea (loose tea)" appeared in Jingyang of Shaanxi province. Fuzhuan tea was formed and shaped around the early Ming dynasty (1368 AD), and the term of "Shaanxi Jing-Wei Fuzhuan tea" was well known on the silk road, and it was also produced in Anhua, Hunan province by traders from Shaanxi provinces. In 2015, China Tea Circulation Association officially named Jingyang County in Shaanxi province as "the source of Fu Tea". With this in mind, drinking of post-fermented Fuzhuan brick tea is strongly claimed to exert its preventive and therapeutic roles in metabolic disorders, and alleviate the severity of many diseases, such as anti-hyperlipidemia, anti-obesity and anti-hyperglycemia. ${ }^{12-16}$ However, the relationship between the gut microbiota modulatory effects of Fuzhuan tea aqueous extract (FTE) and prevention of liver damage is still not clearly understood.

In this study, FTE as a special microbial-fermented Jing-Wei Fuzhuan brick tea aqueous extract was chosen as experimental material because decocting from boiling water can recover the 
majority of water-soluble bioactive compounds, which is probably responsible for its putative health benefits in tea drinking. ${ }^{12,14}$ On the basis of determining the flavonoid constitute of FTE by HPLC, we further investigated the protective effects of FTE against the liver damage in mice with long-term dietary HF consumption by testing aminotransferase (AST), aspartate aminotransferase (ALT), tumor necrosis factor$\alpha$ (TNF- $\alpha)$, tumor necrosis factor- $\beta$ (TNF- $\beta$ ), superoxide dismutase (SOD), malonaldehyde (MDA) and some other biochemical parameters related to the liver function. Importantly, for the first time, we used the high-throughput sequencing of $16 \mathrm{~S}$ rRNA of mouse colon to analyze the regulatory effects of FTE on HFD-induced intestinal microbiota dysbiosis of mice with liver damage.

\section{Materials and methods}

\subsection{Materials and chemicals}

Fuzhuan brick tea was purchased from Jingwei Fucha production factory in Shaanxi province of China, and identified according to the standard of Pharmacopeia of the People's Republic of China. The voucher specimen of the plant materials was deposited at the Key Laboratory for Hazard Factors Assessment in Processing and Storage of Agricultural Products, College of Food Engineering and Nutritional Science, Shaanxi Normal University, China. Haematoxylin and eosin (H\&E) were the products of Shanghai Lanji Technological Development Co., Ltd. (Shanghai, China). Folin-Ciocalteu reagent, gallic acid, gallocatechin, epigallocatechin, catechin, caffeic acid, epigallocatechin gallate, epicatechin, gallocatechin gallate, epicatechin gallate and theaflavins were all purchased from Sigma (China). Detection kits for aspartate aminotransferase (AST, no. C009-1), aspartate aminotransferase (ALT, no. C010-1), alkaline phosphatase (ALP, no. A059-1), superoxide dismutase (SOD, no. A001-1), glutathione peroxidase (GSH-Px, no. A005) and malonaldehyde (MDA, no. A003-1) were obtained from Nanjing Jiancheng Bioengineering Institute (Nanjing, China). Additionally, Assay kits of total cholesterol (TC, no. 2400065), total triglyceride (TG, no. 2400059), low-density lipoproteincholesterol (LDL-C, no. 2400074) and high-density lipoproteincholesterol (HDL-C, no. 2400065) were purchased from Huili Biotechnology Co. Ltd. (Changchun, China). ELISA kits of interleukin-1 (IL-1, no. CK-E20532), interleukin-6 (IL-6, no. CKE20012), tumor necrosis factor- $\alpha$ (TNF- $\alpha$, no. CK-E20220), and tumor necrosis factor- $\beta$ (TNF- $\beta$, no. CK-E93212) were also produced from Nanjing Jiancheng Bioengineering Institute (Nanjing, China). Chromatographic grade methanol was obtained from Sigma Aldrich China (Shanghai, China). Deionized water was prepared using a Millipore Milli Q-Plus system (Millipore, Bedford, MA, USA). The manufacturer of homogenizer (F6/10-10G) is Shanghai Ferruk Equipment Company. The manufacturer of electronic balance (AL104) is Mettler Toledo Company. The manufacturer of the ELISA (Multiskan Go) is Thermoelectric Corporation of United States. Other chemicals used in the study were of analytic grade and commercially available.

\subsection{Preparation of FTE}

Fuzhuan brick tea's fermentation process is as follows: raw dark tea was moistened by steaming and subjected to temperatures as high as $80{ }^{\circ} \mathrm{C}$ overnight. And then pretreated tea materials were pressed into desired sizes of brick-tea before being placed in the fermentation room for 15 days. Finally, the tea products were packaged and stored in a dry warehouse for ripening (ageing) for at least half a year. ${ }^{17,18}$ Briefly, Fuzhuan brick tea was crushed by a crushing machine, and then the crushed powder was screened over 300 eyes to remove the large particles of Fuzhuan brick tea. The powder of Fuzhuan brick tea was extracted by boiling water $\left(100{ }^{\circ} \mathrm{C}\right)$ for 30 minutes $(\mathrm{v} / \mathrm{v}=1 / 20)$ with gentle stirring. At room temperature, it was filtered through three layers of gauze to remove insoluble matter. The filtered solution was lyophilized in a Christ freeze dryer and stored at $-20{ }^{\circ} \mathrm{C}$ until use.

\subsection{Chemical analysis of FTE}

The total polyphenol content of FTE was determined by a modified Folin-Ciocalteu method with gallic acid as a standard. The soluble polysaccharides content of FTE was determined by anthrone-sulfuric acid colorimetry. The total protein content of FTE was determined by Kjeldahl method. The absorbance of five calibration solutions of glucose (100-800 $\mu \mathrm{g}$ $\mathrm{mL}^{-1}$ ) was determined at $760 \mathrm{~nm}$ by using a spectrophotometer, and the standard curve was drawn with absorbance as ordinate and concentration as abscissa. The regression equation was obtained, and the total polyphenol content of FTE was calculated by comparison with a calibration curve $(Y=0.0011 X+$ $\left.0.0888, R^{2}=0.9982\right)$.

Phenolic composition of FTE was analyzed with a HPLC method using a slight adjustment. ${ }^{19}$ The analysis was performed on a reversed-phase $\mathrm{C}_{18}$ column $(4.6 \mathrm{~mm}$ i.d. $\times 250 \mathrm{~mm}$, $5 \mu \mathrm{m}$, Inertsil ODS-SP, Japan) at $30{ }^{\circ} \mathrm{C}$. The analysis of phenolic composition was carried out using a Shimadzu LC-2010A HPLC system which was equipped with an UV detector fixed at $280 \mathrm{~nm}$, and an autosampler and Shimadzu Class VP 6.1 workstation (Shimadzu, Kyoto, Japan). The mobile phase A consisted of ultrapure water containing $0.1 \%$ methanoic acid, while the mobile phase B was $100 \%$ methyl alcohol using a gradient elution of 18-18-34-35-38-60-18\% B by a linear change from $0-2-5-8-16-22-26 \mathrm{~min}$. The flow rate was 1 $\mathrm{mL} \min ^{-1}$ and the injection volume was $10 \mu \mathrm{L}$.

\subsection{Animals and experiment design}

All the mice received human care in compliance with institutional guidelines (XJYYLL-2015689). A total of 30 healthy male Kunming mice (4 weeks old with similar body weight) were purchased from Experimental Animal Center of the Fourth Military Medical University (Xi'an, China). Ten mice were housed in one cage in an animal room at $23 \pm 2{ }^{\circ} \mathrm{C}$ with a 12/ $12 \mathrm{~h}$ light/dark cycle (8:00-20:00) for 1 week of acclimation, with free access to tap water and a standard rodent chow. Chow diet contained all the nutrients required for the healthy growth and development of mice. After one week of adaptation to the 
laboratory environment, the mice were divided averagely into the following three groups with 10 mice each: normal control group (ND group), HF diet control group (HFD group), FTE treated group (FTE group). In the ND group, the mice received tap water and were administered intragastrically (ig, $0.4 \mathrm{~mL}$ ) with physiological saline continuously for 13 weeks once daily. In HFD group, the mice received $30 \% \mathrm{HF}$ water and were administered with physiological saline (ig, $0.4 \mathrm{~mL}$ ) once daily. In FTE group, the mice received $30 \% \mathrm{HF}$ water and were administrated with $400 \mathrm{mg}$ per $\mathrm{kg}$ bw FTE (ig, $0.4 \mathrm{~mL}$ ) once daily according the previous results of our pre-experiment in animals. $^{20}$ Two hours after the last administration, all the mice were fasted but allowed free access to water as usual for $12 \mathrm{~h}$, and the $12 \mathrm{~h}$ urine and feces of the tested mice were collected. All the animals were fully anesthetized by the inhalation of isoflurane and weighed, and then sacrificed to obtain blood and livers. On the basis of the records of the body weight and the corresponding liver weight of each mouse, we calculated the hepatosomatic index (HI) according to the following formula: $\mathrm{HI} \%=$ liver weight/body weight $\times 100 \%$. Additionally, the samples of blood were centrifuged at $1200 \mathrm{~g}$ for $20 \mathrm{~min}$, and stored at $4{ }^{\circ} \mathrm{C}$, while the livers were frozen at $-80{ }^{\circ} \mathrm{C}$ for further analysis. All experimental procedures used in this research were approved by the Committee on Care and Use of Laboratory Animals of the Fourth Military Medical University, China.

\subsection{Measurement of serum parameter}

Assay for serum TC, TG, HDL-C, LDL-C, AST, ALT, and ALP levels was performed with corresponding commercial kits following the manufacturer's instruction, respectively, and the results were expressed as $\mathrm{mmol} \mathrm{L}^{-1}$, mmol $\mathrm{L}^{-1}, \mathrm{mmol}$ $\mathrm{L}^{-1}$, mmol $\mathrm{L}^{-1}$, $\mathrm{mmol}^{-1}$, $\mathrm{mmol} \mathrm{L}^{-1}$, and $\mathrm{mmol} \mathrm{L}^{-1}$, respectively.

\subsection{Measurement of hepatic biochemical parameters}

$1.0 \mathrm{~g}$ of sheared hepatic tissue pieces was added to $9 \mathrm{~mL}$ cold normal saline, and the resultant mixture were homogenized and then were centrifuged at $3000 \mathrm{~g}$ for $10 \mathrm{~min}$. The supernatant of homogenized liver was used for the assay of hepatic MDA, SOD, GSH-Px, IL-1, IL-6, TNF- $\alpha$, TNF- $\beta$ levels, which were performed with corresponding commercial kits (Nanjing Jiancheng Bioengineering Institute, Nanjing, China) following the manufacturer's instruction.

\subsection{Histological analysis and morphometry}

The liver of mice was removed from the left lobe, fixed with $4 \%$ paraformaldehyde, and was performed for histopathological analysis. ${ }^{21}$ The liver of mice was removed from the left lobe, fixed with $4 \%$ paraformaldehyde, and was performed for histopathological analysis. ${ }^{22}$ For Oil Red O staining, the frozen liver samples was processed using cryostat (CM1950, Leica, Germany) and then fixed and stained. ${ }^{21}$ These slides were found under the Olympus light microscope for observations and photograph. Finally, the images were examined and evaluated for pathological change analysis.

\subsection{High-throughput sequencing of 16S rRNA}

Used CTAB methods to extract genomic DNA of colon content. The final DNA concentration and purification were determined by NanoDrop 2000 UV-vis spectrophotometer (Thermo Scientific, Wilmington, USA), and DNA quality was checked by $1 \%$ agarose gel electrophoresis. According to the selections of sequencing areas, we used diluted genomic DNA as templates, used specific primers with barcode, and used High-Fidelity PCR Master Mix with GC buffer (New England Biolabs company) for 16S rRNA gene PCR amplification (V3 and V4 with pyrosequencing tagged forward 5'-TCCTACGGGAGGCAGCAGT-3' and reverse $5^{\prime}$-GGACTACC AGGGTATCT-AAT-CCTGTT-3' primer with cycling conditions of $95{ }^{\circ} \mathrm{C}$ for $30 \mathrm{~s}$ and $60{ }^{\circ} \mathrm{C}$ for $1 \mathrm{~min}$, using 30 cycles). ${ }^{23,24}$ According to the concentration of PCR products, the samples were mixed equally and purified by agarose gel electrophoresis of $2 \%$ concentration. The product purification kit is Gene JET gum recovery kit (Thermo Scientific Co.). The Ion Plus Fragment Library Kit 48 rxns (Thermo Fisher company) were used to construct the library. The constructed library passed the Qubit quantitative and library test, and then the Ion S5TMXL (Thermo Fisher company) was used to carry out the on-machine sequencing.

\subsection{Statistical analysis}

Results of polyphenol contents, weights of mouse body, serum and hepatic biochemical parameters were expressed as means $\pm \mathrm{SD}$, and were analyzed with Prism 5 . Statistical significance for the results of serum and hepatic biochemical test was determined by one-way analysis of variance followed by LeastSignificant Difference (LSD) test. ANOVA was performed using SPSS20 (IBM) and $p<0.05$ was considered statistically significant.

\section{Results}

\subsection{Chemical properties of FTE}

The results showed that the contents of total polyphenols, total flavonoids, soluble polysaccharides, and total protein in FTE were $164.24 \pm 7.26 \mathrm{mg} \mathrm{g}^{-1}, 124.19 \pm 6.69 \mathrm{mg} \mathrm{g}^{-1}, 44.95 \pm$ $3.66 \mathrm{mg} \mathrm{g}^{-1}$ and $47.83 \pm 5.05 \mathrm{mg} \mathrm{g}^{-1}$, respectively. Furthermore, the main polyphenols of FTE was identified and quantified by a validated HPLC-UV technique and the results were shown in Fig. 1. Ten peaks were identified in the order of gallic acid (6.43 $\mathrm{min})$, gallocatechin (7.16 $\mathrm{min})$, epigallocatechin (8.90 $\mathrm{min})$, catechin (9.39 min), caffeic acid (10.87 min), epigallocatechin gallate (11.47 $\mathrm{min})$, epicatechin (12.06 $\mathrm{min})$, gallocatechin gallate (13.10 $\mathrm{min})$, epicatechin gallate (15.64 $\mathrm{min})$, theaflavins (23.87 $\mathrm{min}$ ) by comparison with the retention time $\left(t_{\mathrm{R}}\right)$ of the commercial standards under the same conditions. As depicted in Table 1, linear regression was used for the calculation, and a good linearity with the correlation coefficients $\left(R^{2}\right)$ in the range of 0.9937-0.9999 was obtained, and the concentrations of gallic acid, gallocatechin, epigallocatechin, catechin, caffeic acid, epigallocatechin gallate, epicatechin, gallocatechin gallate, epicatechin gallate and theaflavins in FTE were $21.44 \pm$ $0.09,26.56 \pm 0.11,67.70 \pm 0.79,10.48 \pm 0.16,22.27 \pm 0.16$, 

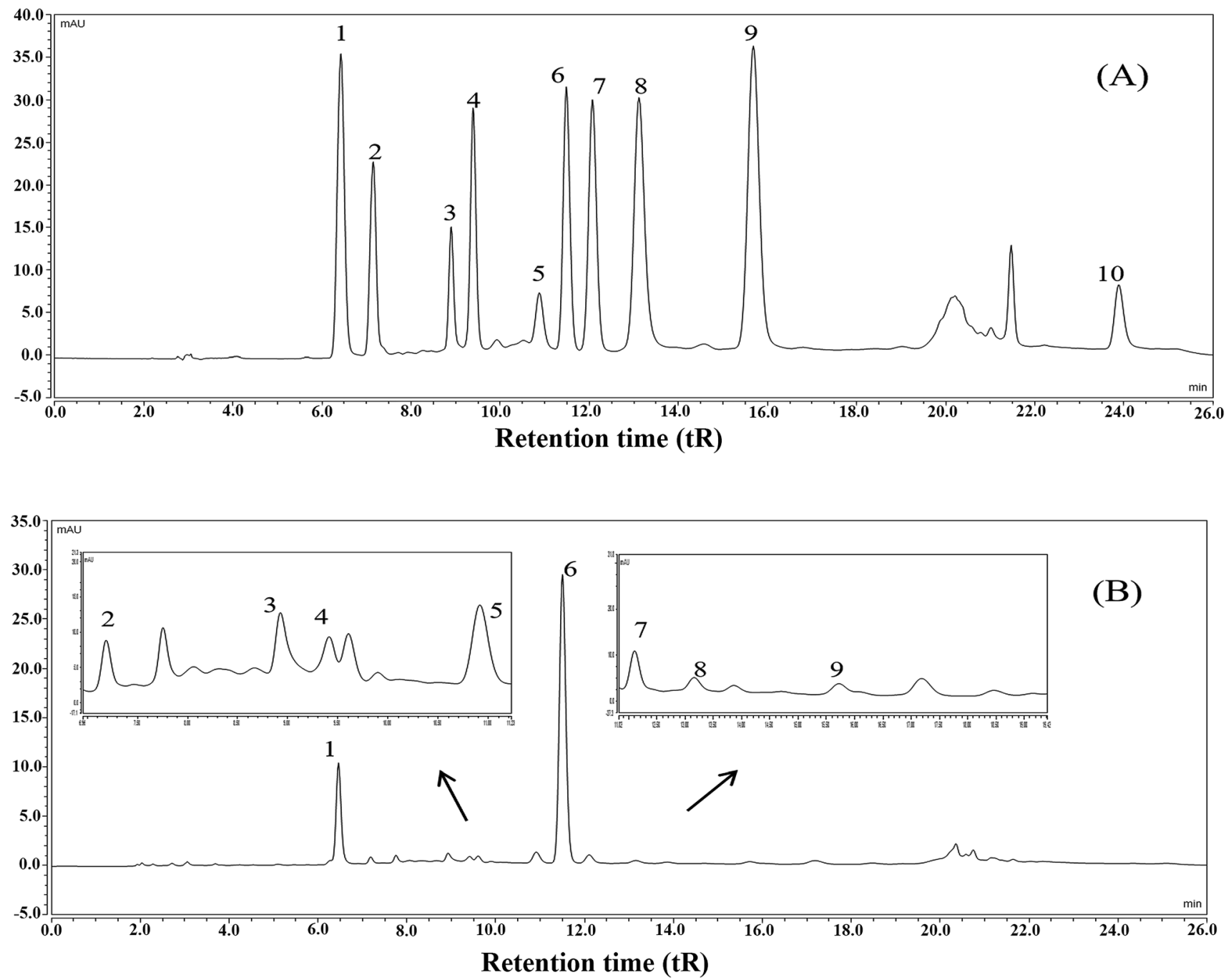

Fig. 1 HPLC chromatograms of the mixed standards (A), the aqueous extract of Fuzhuan brick tea, named FTE (B). HPLC peaks: (1) gallic acid, (2) gallocatechin, (3) epigallocatechin, (4) catechin, (5) caffeic acid, (6) epigallocatechin gallate, (7) epicatechin, (8) gallocatechin gallate, (9) epicatechin gallate, (10) theaflavins.

$111.93 \pm 0.06,6.12 \pm 0.03,3.79 \pm 0.14,1.11 \pm 0.01$ and $4.84 \pm$ $0.26 \mathrm{mg} \mathrm{g}^{-1}$, respectively. As a result, the main flavonoid of FTE was identified as epigallocatechin gallate, followed by epigallocatechin and gallocatechin.

\subsection{Effects of FTE on body weight, liver weight and HI in HFD-fed mice}

As shown in Table 2, after giving 30\% fructose water for 13 weeks, the average food and water intake was not significantly

Table 1 Calibration curves and the contents of the identified polyphenols in FTE by HPLC ${ }^{a}$

\begin{tabular}{|c|c|c|c|c|c|}
\hline Peak no. & $t_{\mathrm{R}}(\min )$ & Identified/polyphenols & Regression equation $Y=a X+b$ & $R^{2}$ & Content $^{b}\left(\mathrm{mg} \mathrm{g}^{-1}\right)$ \\
\hline 1 & 6.43 & Gallic acid & $Y=5.9167 X+0.4124$ & 0.9998 & $21.44 \pm 0.09$ \\
\hline 2 & 7.16 & Gallocatechin & $Y=87.147 X-14.651$ & 0.9992 & $26.56 \pm 0.11$ \\
\hline 4 & 9.39 & Catechin & $Y=21.611 X+3.4979$ & 0.9995 & $10.48 \pm 0.16$ \\
\hline 5 & 10.87 & Caffeic acid & $Y=23.684 X+8.7968$ & 0.9992 & $22.27 \pm 0.16$ \\
\hline 6 & 11.47 & Epigallocatechin gallate & $Y=8.7325 X+0.6203$ & 0.9996 & $111.93 \pm 0.06$ \\
\hline 9 & 15.64 & Epicatechin gallate & $Y=4.5062 X-0.6542$ & 0.9984 & $1.11 \pm 0.01$ \\
\hline 10 & 23.87 & Theaflavins & $Y=23.073 X+3.0737$ & 0.9937 & $4.84 \pm 0.26$ \\
\hline
\end{tabular}

${ }^{a} Y$ is the characteristic peak area in HPLC chromatograms, and $X$ is the concentration of the samples. ${ }^{b}$ Contents of each component in FTE is expressed as $\mathrm{mg} \mathrm{g}^{-1}$ dried extract. 
different $(p>0.05)$ among all the tested groups. However, the high fructose diet (HFD)-fed mice showed a significant increase in the body weight, liver weight and HI, when compared to the untreated normal diet (ND) mice $(p<0.05)$. Interestingly, a HFDinduced increase in body weight of mice could be effectively decreased by the oral administration of FTE at $400 \mathrm{mg}$ per $\mathrm{kg}$ bw $(p<0.05)$. Similarly, an increase in the liver weight and HI of HFD feeding mice was also significantly inhibited by FTE treatment in HFD-fed mice $(p<0.05)$.

\subsection{FTE balanced serum lipid homeostasis}

The serum TC, TG, HDL-C and LDL-C levels in mice were displayed in Fig. 2A-D, respectively. After giving high concentrations of high fructose (30\%), the mice had a significant increase in TC, TG and LDL-C levels, respectively $(p<0.05)$. Interestingly, FTE treatment caused a significant decrease in TG and LDL-C levels by $36.4 \%(p>0.05)$ and $67.7 \%(p<0.05)$ in comparison with HFD control feeding in mice, respectively, but FTE caused a puny decrease in TC by $6.30 \%(p>0.05)$. Furthermore, Fig. $2 \mathrm{C}$ displays the level of serum HDL-C, where the content of HDL-C after HFD feeding was dramatically decreased by $91.0 \%$, relative to ND-fed mice $(p<0.05)$. As expected, application of FTE caused a 1.68-fold increase in HDL-C level of mice when compared to HFD-fed mice $(p<0.05)$, suggesting that FTE might normalize the lipid disorders via improving the serum lipid profiles in HFD-fed mice. For Oil Red O staining, the liver sections of HFD-fed mice showed excessive accumulation of lipid droplets inside the parenchyma cells, relative to ND mice (Fig. $2 \mathrm{E}(\mathrm{d}$ and $\mathrm{e})$ ). Interestingly, the number and volume of hepatic fat granules in the mice treated with FTE $(400 \mathrm{mg}$ per $\mathrm{kg}$ bw) was slightly reduced as compared to that in HFD-fed mice (Fig. 2E(f)).

\subsection{FTE effectively modulated oxidative stress in mouse livers}

Liver damage is usually accompanied by oxidative stress. ${ }^{25}$ As shown in Fig. 3A, a HFD-caused dramatic increase $(p<0.05)$ in the hepatic content of MDA, a key index of oxidative stress for the chain reaction of lipid peroxidation, was inhibited by 3.07fold $(p<0.05)$ in the mice exposed to FTE. The hepatic enzyme activities of SOD and GSH-Px in the experimental mice are shown in Fig. 3B and C, and it was found that SOD and GSH-Px activities in the liver of mice administered $30 \%$ HF water were significantly lowered by approximately $59.8 \%$ and $23.2 \%$, compared to ND mice, respectively $(p<0.05)$. However, FTE at $400 \mathrm{mg}$ per $\mathrm{kg}$ bw increased hepatic enzyme SOD and GSH-Px activities by 1.19 -fold $(p<0.05)$ and 0.13 -fold $(p>0.05)$ in comparison with HFD control feeding in mice, respectively. This results suggest that FTE displayed a significant protective effect against the liver injury in mice.

\subsection{Effects of FTE on hepatic inflammation}

As shown in Fig. 4A-D, continuous 13 weeks ingestion of 30\% HF water in mice prominently led to an increase in hepatic IL-1, IL-6, TNF- $\alpha$ and TNF- $\beta$ levels by $41.8 \%(p<0.05), 130.4 \%(p<$ $0.05), 156.3 \%(p<0.05)$ and $566.6 \%(p<0.05)$, respectively, suggesting the significant inflammation in mice. The IL-1 and TNF- $\beta$ levels of the mice treated with FTE were slightly decreased by $30.7 \%$ (Fig. $4 \mathrm{~A}, p<0.05$ ) and $47.1 \%$ (Fig. $4 \mathrm{D}, p<$ 0.05 ), and interestingly, this FTE administration could significantly reduce IL-6 and TNF- $\alpha$ levels in HFD-treated mice by $69.4 \%$ (Fig. $4 \mathrm{~B}, p<0.05$ ) and $60.3 \%$ (Fig. $4 \mathrm{C}, p<0.05$ ) respectively, suggesting that FTE had strong protective effects against HFD-induced liver injury involved in abnormal lipid profile including IL-1, IL-6, TNF- $\alpha$ and TNF- $\beta$ of mice.

\subsection{Effects of FTE on hepatic damage biomarkers and histopathological changes}

AST, ALT and ALP activities are considered to be effective biochemical markers of early hepatic damage. ${ }^{26}$ As described in Fig. 4E-G, the enzymatic activities of serum AST, ALT and ALP activities in HFD-treated mice were remarkably increased to $2.26 \pm 0.16 \mathrm{mmol} \mathrm{L}^{-1}(p<0.05), 1.88 \pm 0.08 \mathrm{mmol} \mathrm{L}^{-1}(p<0.05)$ and $1.91 \pm 0.17 \mathrm{mmol} \mathrm{L}^{-1}(p<0.05)$ from $1.59 \pm 0.04 \mathrm{mmol} \mathrm{L}^{-1}$, $1.40 \pm 0.12 \mathrm{mmol} \mathrm{L}^{-1}$ and $0.41 \pm 0.28 \mathrm{mmol} \mathrm{L}^{-1}$ of ND-fed mice, respectively, indicating that HFD intake caused hepatotoxicity in mice. Interestingly, FTE significantly reduced the AST, ALT and ALP activities by $28.7 \%(p<0.05), 28.8 \%(p<0.05)$ and $82.6 \%(p<0.05)$, as compared to HFD-fed mice, suggesting that administration of FTE possessed the potential for

Table 2 Food intake, water intake, body weight, liver weight and hepatosomatic index of mice at the end of week $13^{a}$

\begin{tabular}{llll}
\hline & Groups & & \\
\cline { 2 - 4 } Index & Normal & HFD & FTE \\
\hline Food intake $\left(\mathrm{g} \mathrm{d}^{-1}\right)$ & $10.51 \pm 2.11^{\mathrm{a}}$ & $10.14 \pm 2.62^{\mathrm{a}}$ & $9.99 \pm 2.70^{\mathrm{a}}$ \\
Water intake $\left(\mathrm{mL} \mathrm{d}^{-1}\right)$ & $6.45 \pm 2.47^{\mathrm{a}}$ & $7.21 \pm 2.34^{\mathrm{a}}$ & $7.37 \pm 2.23^{\mathrm{a}}$ \\
Fructose intake $(\mathrm{g}$ per day) & - & $2.16 \pm 0.70^{\mathrm{a}}$ & $3.21 \pm 0.67^{\mathrm{a}}$ \\
Initial body wt $(\mathrm{g})$ & 32.21 & 41.82 & 30.58 \\
Final body wt $(\mathrm{g})$ & $42.77 \pm 3.22^{\mathrm{ab}}$ & $1.70 \pm 0.17^{\mathrm{b}}$ & $42.31 \pm 4.02^{\mathrm{b}}$ \\
Liver wt $(\mathrm{g})$ & $1.48 \pm 0.08^{\mathrm{a}}$ & $3.59 \pm 0.11^{\mathrm{a}}$ & $1.49 \pm 0.17^{\mathrm{a}}$ \\
HI $(\%)$ & $3.46 \pm 0.09^{\mathrm{a}}$ & & $3.51 \pm 0.18^{\mathrm{a}}$
\end{tabular}

\footnotetext{
${ }^{a}$ Hepatosomatic index: liver weight $(\mathrm{g}) /$ body weight $(\mathrm{g})$. Values were expressed as means \pm SD of 10 mice in each group and different letters in the same row indicated significant differences at $p<0.05$. Normal: a normal diet (ND) group; HFD: high-fructose diet group; FTE: FTE-treated group of the mice.
} 

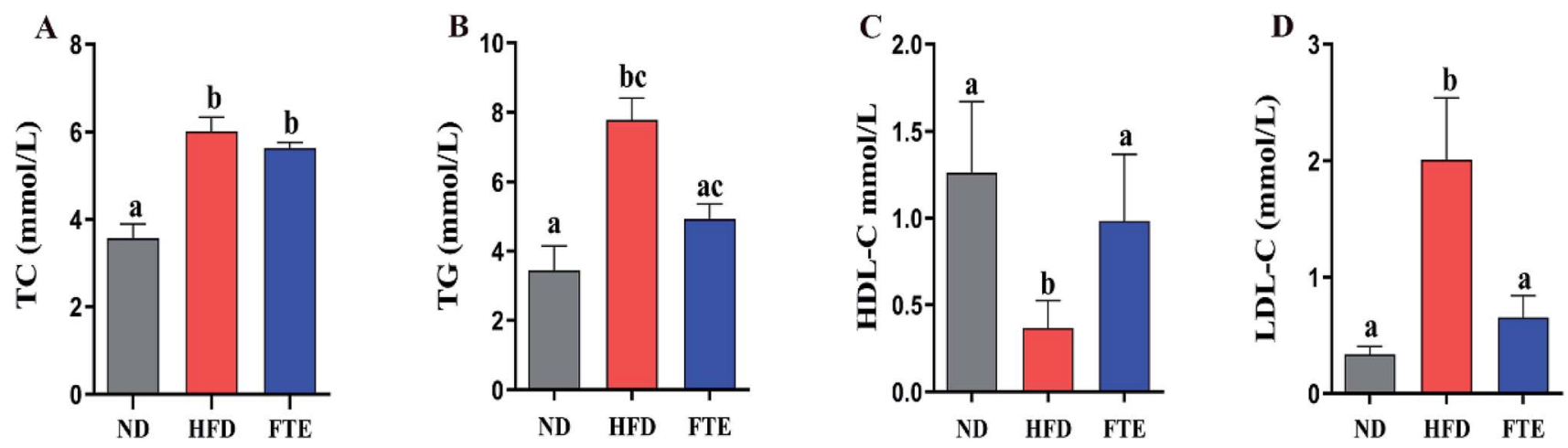

E

ND

HFD

FTE
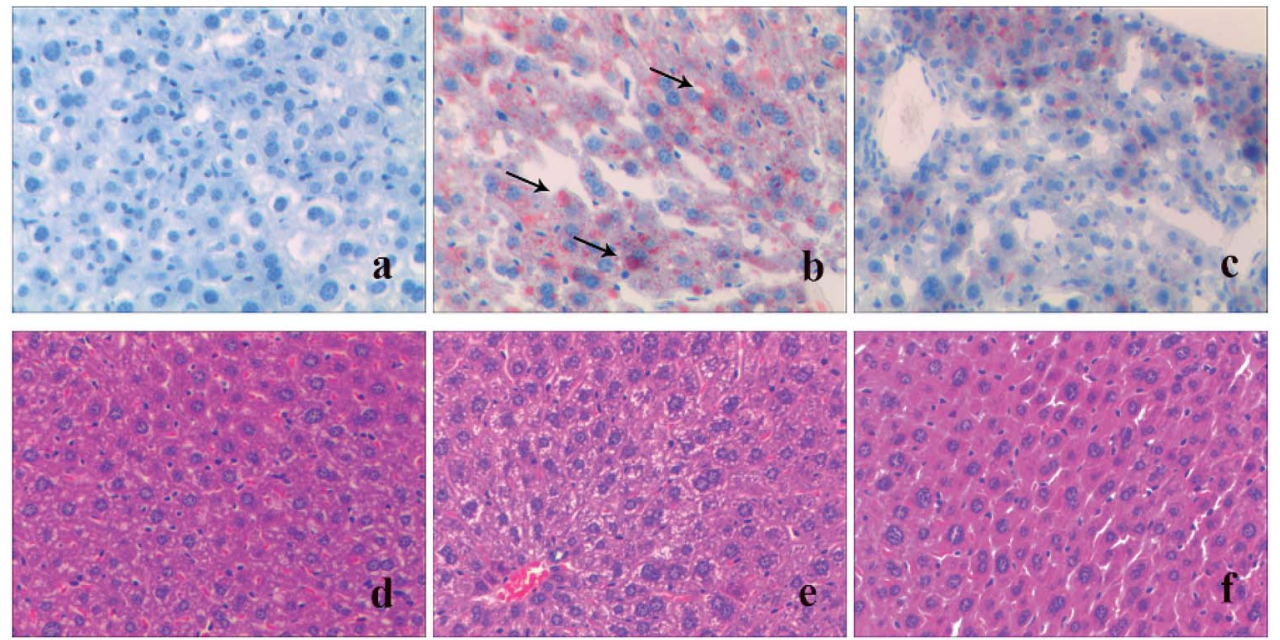

H\&E

Liver
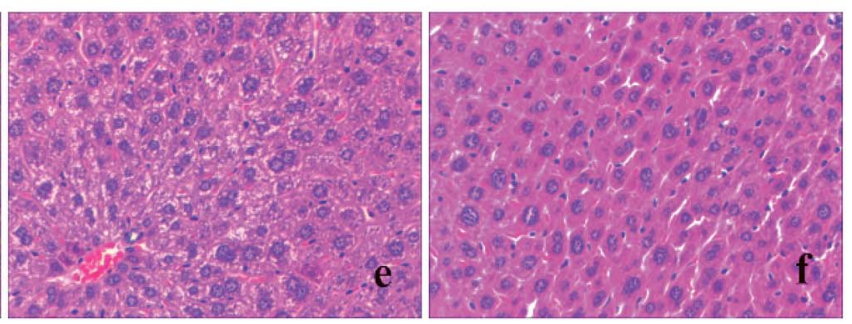

Fig. 2 Effects of FTE on serum TC (A), TG (B), HDL-C (C), LDL-C (D) levels in the mice fed 30\% high fructose diet (HFD) water for consecutive 13 weeks. Data are expressed as means \pm SD for 10 mice in each group. (E) The liver tissue was stained with Oil Red $O$ and $H \& E$, and observed at $200 \times .{ }^{a-c}$ Mean values within a row with different alphabetical letters denote significant differences $(p<0.05)$ among all groups.

management or prevention of HFD-induced hepatic injury in mice.

The photomicrographs of H\&E staining for liver tissue were investigated, and the liver in HFD-fed mice showed ballooned lipid laden hepatocytes, severe cellular degeneration and the loss of cellular boundaries, when compared with ND-fed mice (Fig. 2E(a and b)). As expected, supplementation of FTE at $400 \mathrm{mg}$ per $\mathrm{kg}$ bw showed obvious inhibition against the hepatic injuries caused by HFD, where liver cells had a well-preserved cytoplasm, prominent nucleus and legible nucleoli, which
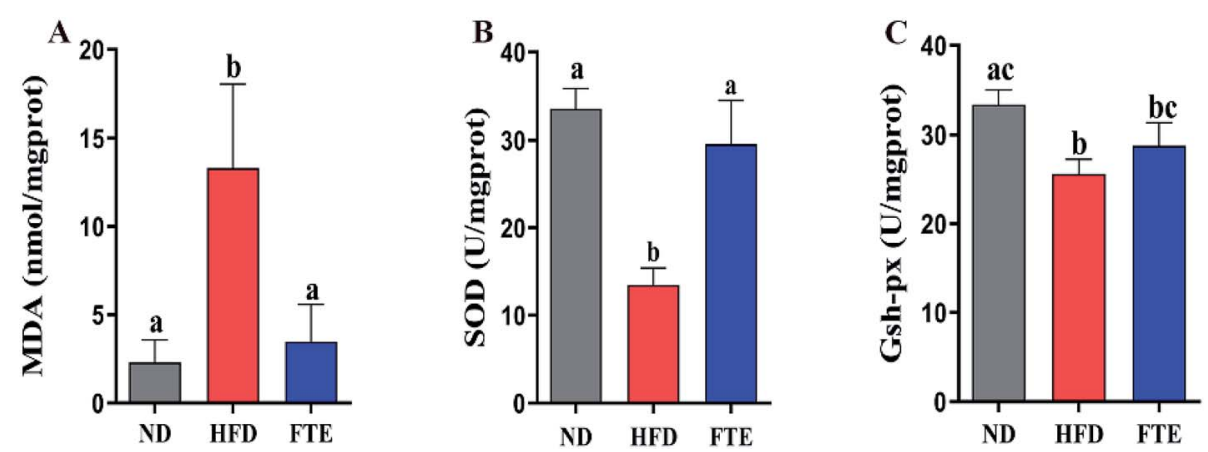

Fig. 3 Effects of FTE on hepatic MDA (A), SOD (B), GSH-Px (C) levels in HFD-fed mice for consecutive 13 weeks. Data are expressed as means \pm SD for 10 mice in each group. ${ }^{a-c}$ Mean values within a row with different alphabetical letters denote significant differences $(p<0.05)$ among all groups. 
A

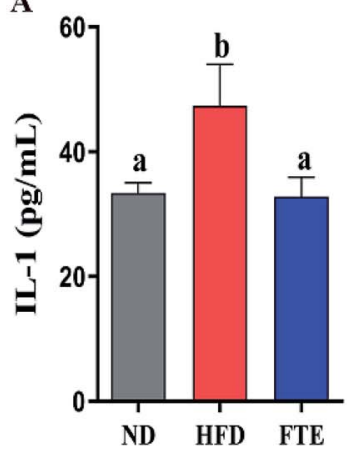

B

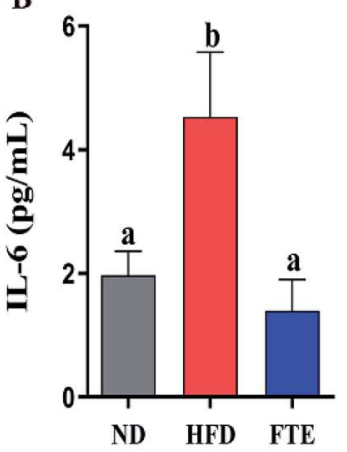

C

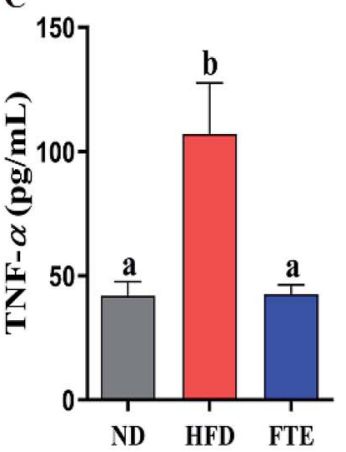

D

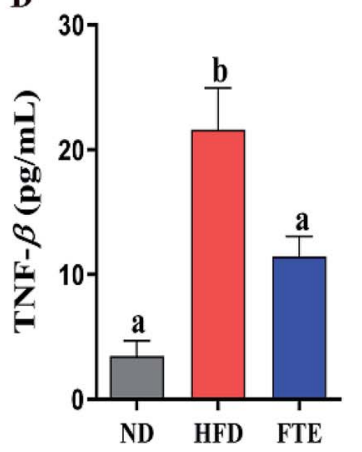

E

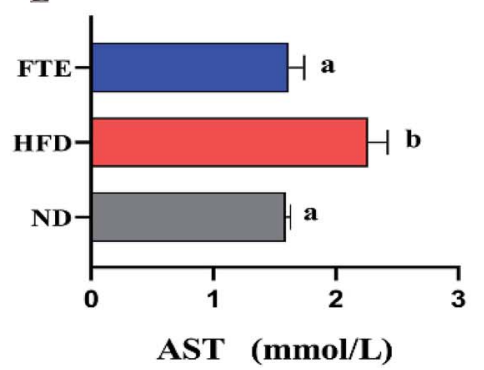

F

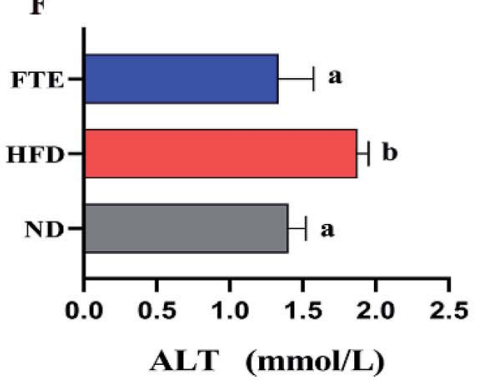

G

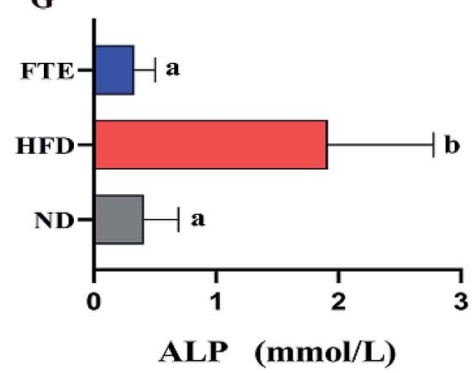

Fig. 4 Effects of administration of FTE on hepatic levels of IL-1 (A), IL-6 (B), TNF- $\alpha(C)$, and TNF- $\beta$ (D), and serum enzymatic activities of AST (E), ALT (F) and ALP (G) against HFD-induced liver damage in mice. Data are expressed as means \pm SD for 10 mice in each group. ${ }^{\text {a,b }}$ Mean values within a row with different alphabetical letters denote significant differences $(p<0.05)$ among all groups.

were near the exterior of the liver in ND mice (Fig. 2E(c)). For Oil Red $O$ staining, the number and volume of hepatic fat granules in the mice treated with FTE ( $400 \mathrm{mg}$ per $\mathrm{kg}$ bw) was slightly reduced as compared to that in HFD-fed mice (Fig. $2 \mathrm{E}(\mathrm{f})$ ). The above observation indicated that FTE had significant protective effects on liver injury caused by HFD feeding.

\subsection{Structural change of gut microbiota in response to HFD and FTE}

The Venn diagrams were used to compare the similarity of the OTU of samples (Fig. 5A), and there was $74.3-85.1 \%$ of OTU similarity among the three experimental groups, but there were $8.46 \%$ and $9.66 \%$ of OTU difference between ND and FTE groups when compared to that in HFD group, respectively, indicating that there was different abundance of microorganisms among the three tested groups. In addition, changes in microbial communities were investigated using the Chao 1 and Shannon-Wiener diversity index. As shown in Fig. 5B, HFD feeding significantly lowered the Shannon-Wiener diversity index, relative to ND control, whereas FTE administration in mice increased it, where there were significant difference in Shannon-Wiener diversity between HFD-fed mice and FTEtreated mice $(p<0.5)$. However, Chao 1 plot showed no significant difference between any two groups (Fig. 5C). These results indicated that different treatments had differentiated effects on microbial richness, and in general, FTE application in HFD-fed mice increased the microbial richness and diversity. As depicted in Fig. 5D, Non-Metric Multi-Dimensional Scaling (NMDS) based on the unweighted Unifrac distances indicated significant clustering by diet type with complete separation of the colonic microbiota of ND- and FTE-treated mice from that of HFD-fed mice along the MDS1 axis, showing that there was a difference in intestinal microbiota among the three groups.

At phylum level, a relative abundance bar from the selected top 10 species in each test based on the species taxonomic level was present in Fig. 5E. It was found that the intestinal microbial structure of mice was mainly dominated by Firmicutes and Bacteroidetes at phylum level, while Actinobacteria and Proteobacteria contributed relatively smaller proportion to the intestinal microbiota community. To be specific, continuous 13 weeks ingestion of $30 \% \mathrm{HF}$ water in mice prominently led to an increase in relative abundance of Firmicutes by $51.7 \%(p>0.05)$ and a decrease in relative abundance of Bacteroidetes by $34.4 \%$ $(p<0.05)$ in comparison with the untreated ND-fed mice (Fig. 5E and $6 \mathrm{~A}$ and $\mathrm{B}$ ), resulting in an elevation of the Firmicutes/ Bacteroidetes ratio in HFD-fed mice. Interestingly, FTE treatment caused a $39.5 \%$ decrease in relative abundance of Firmicutes $(p<0.05)$ and a $42.1 \%$ increase in relative abundance of Bacteroidetes $(p>0.05)$, related to HFD-fed mice, respectively (Fig. 5E and 6A and B). HFD also induced the obvious elevations in the relative abundance of Proteobacteria (from 2.95 to $6.36 \%$ ) and Tenericutes (from 0.22 to $1.95 \%$ ) from ND control (Fig. $5 \mathrm{E}$ and $6 \mathrm{C}$ and $\mathrm{D} ; p<0.05)$. However, FTE intervention exerted inhibitory effects on the relative abundances of Proteobacteria 
A

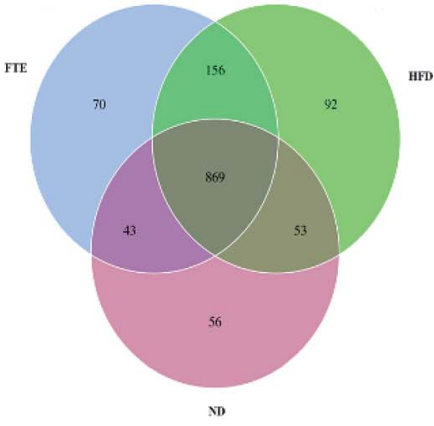

D

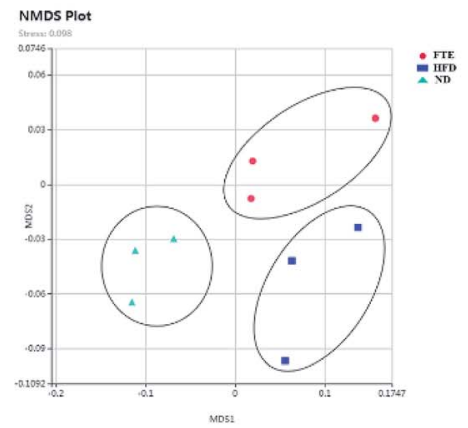

B

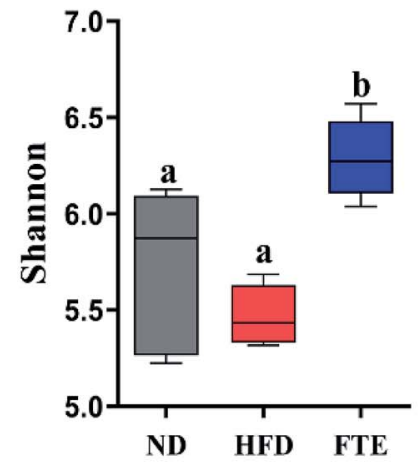

E

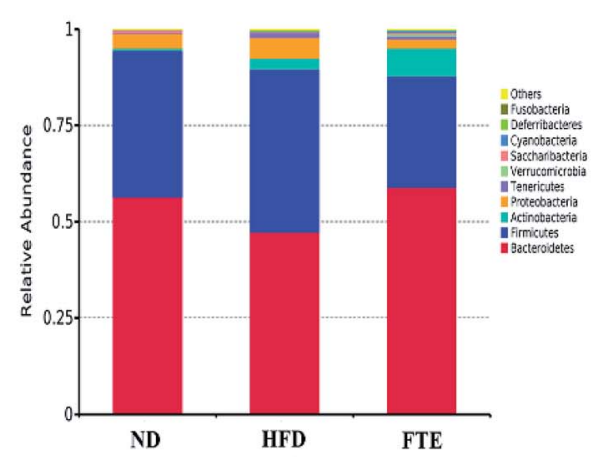

C

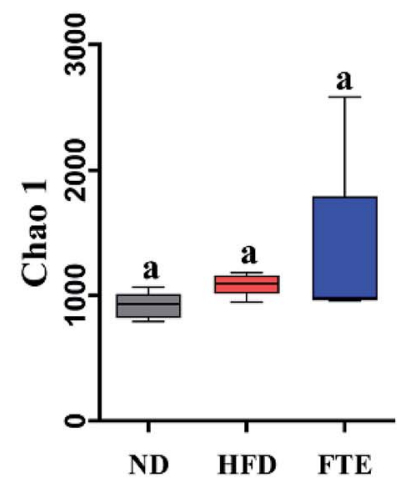

F

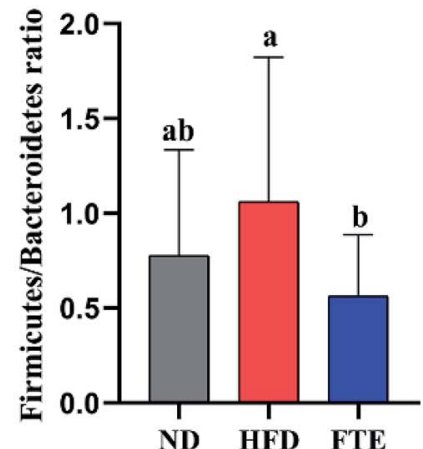

G
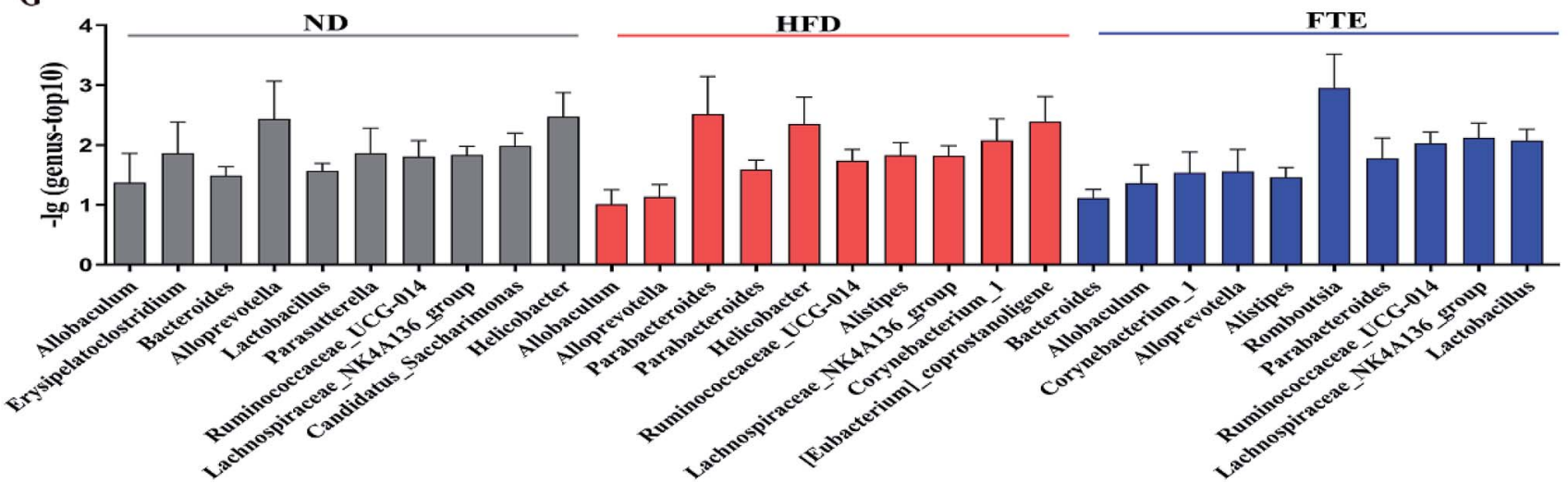

Fig. 5 Effects of FTE or HFD treatment on the composition of colon microbiota. (A) Venn diagram of three groups based on OUT. (B) A plot of the Shannon-Wiener diversity index. (C) A plot of the Chao 1 index. (D) The Non-Metric Multi-Dimensional Scaling (NMDS) analysis score plot of colon microbiota based on unweighted Unifrac distances between the three groups. (E) The relative abundance of top 10 of intestinal microbiota in colon at phylum level. Others represent other microbiota expect top 10 of all. (F) The ratio of Firmicutes to Bacteroidetes. (G) The relative abundance of top 10 of colon microbiota at genus level in each group.

and Tenericutes in HFD feeding mice (Fig. 5E and 6C and D; $p<$ $0.05)$.

At the genus level, we selected the top 10 species with the highest relative abundance in each group to build up the species taxonomic level. As can been seen in Fig. 5G, the dominant strains in HFD-fed mice were Parabacteroides and Helicobacter, while they were Bacteroides and Lactobacillus in ND- and FTE-treated mice. In addition, a distinct increase in Allobaculum (from 4.53 to $33.7 \%, p<0.05$ ) and Helicobacter (from 0.09 to $4.45 \%, p<0.05$ ), and the decreases in population of Bacteroides (from 7.39 to $4.65 \%, p>0.05$ ) and Lactobacillus (from 3.39 to $0.32 \%, p<0.05$ ) were observed in HFD-treated mice when compared to ND mice (Fig. 6E-H). However, treatment of mice with FTE could lead to the significant decreases in relative abundance of Allobaculum and Helicobacter by $74.0 \%(p<0.05)$ and $94.1 \%(p<0.05)$ and a certain degree of increases in relative abundance of Bacteroides and Lactobacillus by $121.4 \%(p<0.05)$ and $345.3 \%(p>0.05)$, related to HFD feeding mice, respectively. In our hands, linear discriminant analysis (LDA) effect size (LEfSe) algorithm was applied to further identify the most differentially abundant taxa between the three tested groups. As shown in Fig. 6I, the histogram and cladogram generated from LEfSe confirmed that gut microorganism inhabiting in the ND, HFD and FTE treated mice clustered separately. LEfSe detected 11, 6 and 12 bacterial clades showed statistically significant and biologically consistent 


\section{phylum richness $(\% / 100)$}
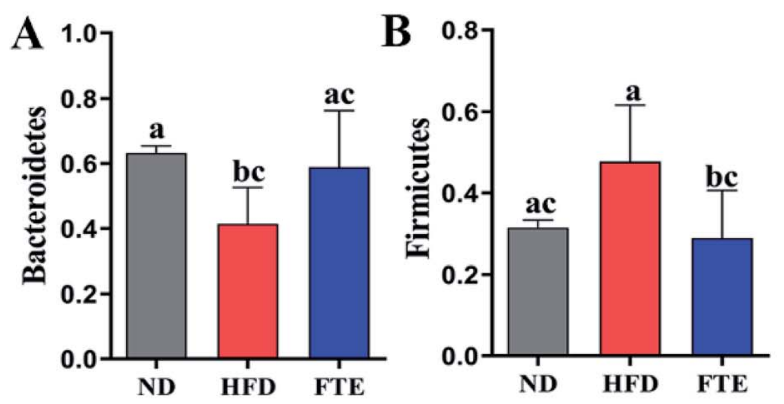

C
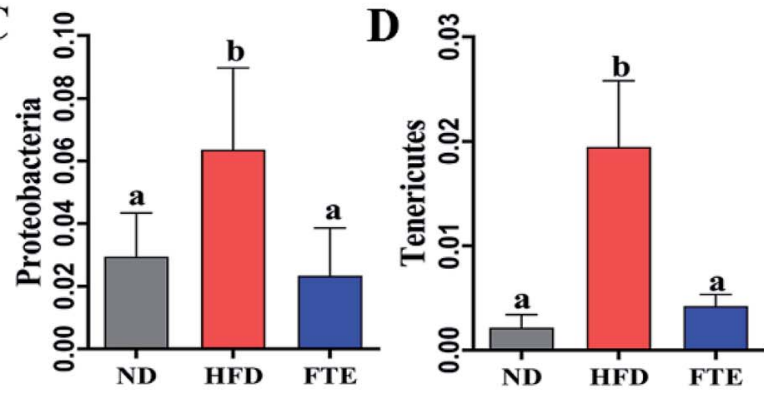

I

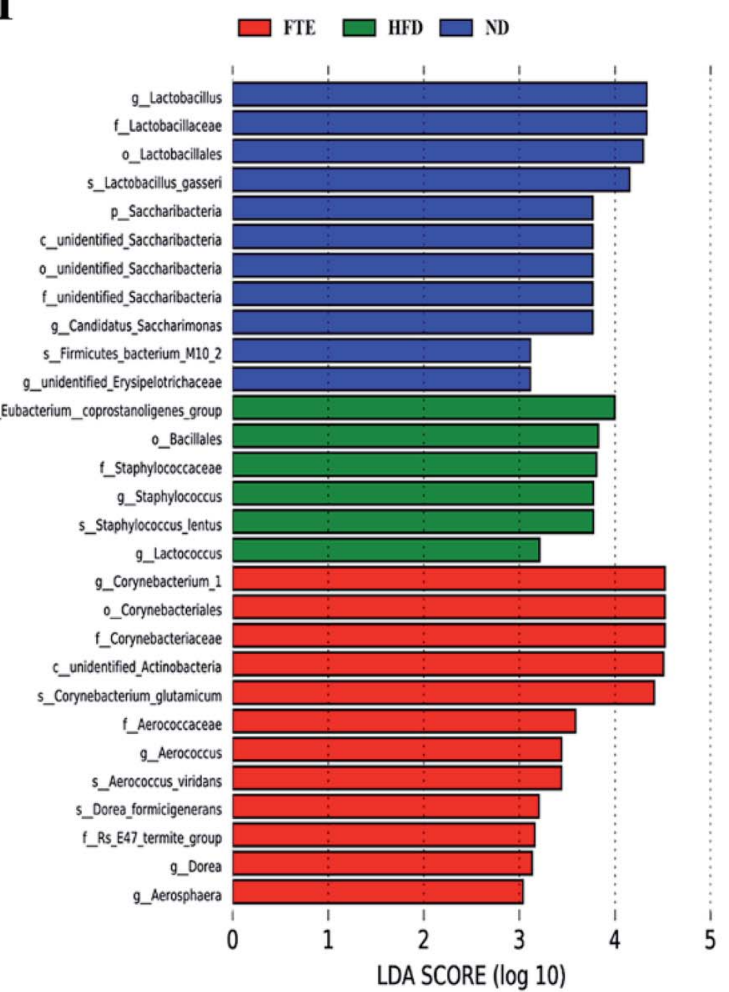

genus richness $(\% / 100)$
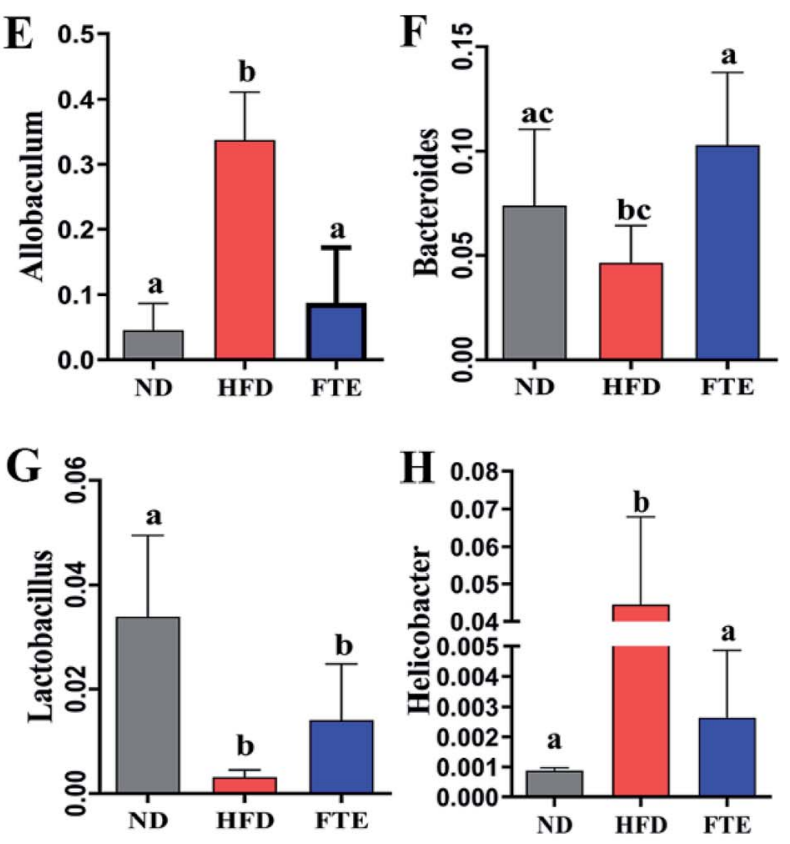

$\mathbf{J}$

Fig. 6 Changes in the intestinal microbiota in FTE-fed mice as compared to HFD control. The relative abundance of (A) Bacteroidetes, (B) Firmicutes, (C) Actinobacteria, (D) Proteobacteria, (E) Allobaculum, (F) Bacteroides, (G) Lactobacillus, and (H) Helicobacter. Bars represent the mean $\pm \mathrm{SD}(n=10)$. Different letters indicate significant statistical differences among groups at $p<0.05$. (I and J) Linear discriminative analysis (LDA) effect size (LEfSe) analyses of statistically significant taxa. Taxa were sorted by degree of difference and overlaid on a taxonomic cladogram. Only the taxa meeting a significant LDA threshold value of $>3.0$ are shown.

differences in the fecal microbiota of ND mice, FTE-treated mice and HFD control mice, respectively. As shown in Fig. 6J, the most differentially abundant bacterial taxa detected in response to FTE administration belonged to the order
Corynebacteriales and the family Corynebacteriaceae, while the most differentially abundant bacterial taxa in response to HFD consumption belonged to the order Baclillales and the family Staphylococcaceae. 

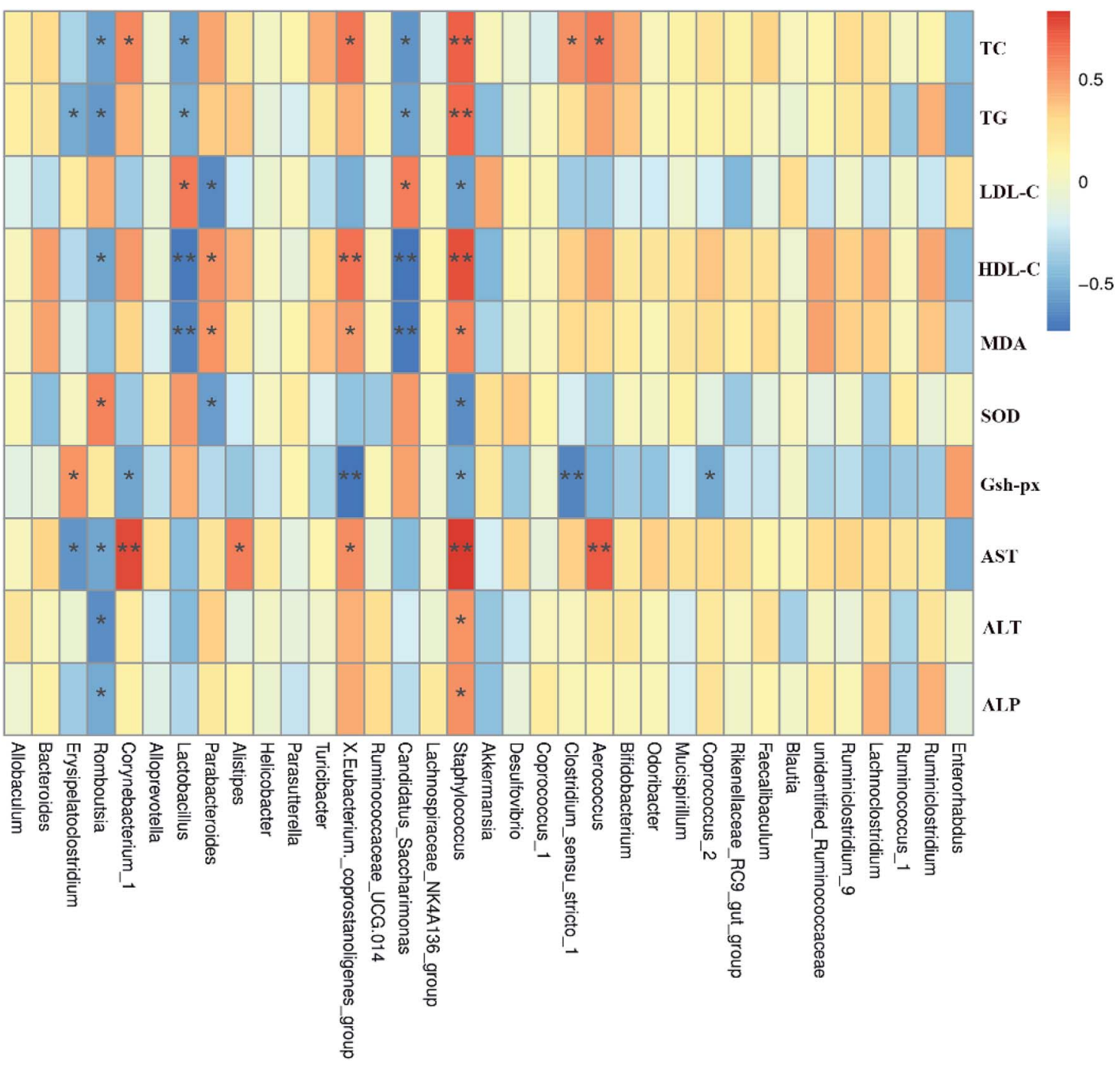

Fig. 7 Spearman's correlation between gut microbiota at genus level and biochemical parameters. Colors of squares represent $R$-value of Spearman's correlation. $p<0.05 *$ and $p<0.01 * *$ indicate the association significant, respectively.

\section{Discussion}

Fructose is a sweetener, but too much fructose intake increases the risk of NAFLD, which is a chronic liver disease related to the composition alteration of the intestinal microbiota. ${ }^{26-28}$ Interestingly, it is claimed that drinking tea has a potential role in the treatment and prevention of liver injury caused by HFD. ${ }^{29-31}$ A special Jing-Wei Fuzhuan brick tea is a unique post-fermented tea which is distinguished from the other post-fermented teas by deliberate fermentation with the probiotics Eurotium cristatum, and exhibits a variety of biological activities, such as antiobesity, antibacterial, and anti-oxidation effects. ${ }^{\mathbf{1 2 - 1 4 , 3 2}} \mathrm{A}$ few reports have mainly focused on the investigation on anti-obesity and anti-oxidation properties of Fuzhuan brick tea, and limited study on the influence of Fuzhuan brick tea against NAFLD is performed, and the regulatory effect of Fuzhuan brick tea on intestinal microbiota was also rarely studied. Herein, FTE as aqueous extract of tea-based drink infusion ingredient was successfully separated from Fuzhuan brick tea and its composition of flavonoids in FTE was principally identified as epigallocatechin gallate $\left(111.93 \pm 0.06 \quad \mathrm{mg}^{-1}\right)$ and epigallocatechin $\left(67.70 \pm 0.79 \mathrm{mg} \mathrm{g}^{-1}\right)$, and interestingly, FTE also contained the unique theaflavin $\left(4.84 \pm 0.26 \mathrm{mg} \mathrm{g}^{-1}\right)$. These flavonoids and polyphenols may be responsible for the health effects claimed by FTE, where catechins and epigallocatechin gallate have been considered as the main components, contributing to the putative beneficial metabolic effects of tea..$^{33-35}$

Previous reports have pointed to liver stress in animals fed with HFD due to the burden of fructose metabolism, and the long-term consumption of HF sweetener has led to obesity and hepatic steatosis. ${ }^{36,37}$ Furthermore, the hepatic lipid metabolism is also associated with the elevated TC, TG, LDL-C and decreased HDL-C levels, and these data once again indicate that long-term feeding of HFD results in obesity and hypertriglyceridemia, which is a key factor in early NAFLD. ${ }^{38,39}$ In this 
study, HFD feeding in mice significantly induced unbalanced changes in the serum TC, TG, HDL-C and LDL-C levels (Fig. 2). As expected, our experimental data showed that FTE could avoid liver injury by balancing the serum TC, TG, HDL and LDL-C levels in HFD-fed mice (Fig. 2), which might be resulted from the decrease in lipid synthesis with regulation of the glycolytic pathway. ${ }^{40}$ Histopathological observation of Oil Red O staining of the tested mouse livers further confirmed the lipid abnormality in HFD-fed mice, characterized by extensive lipid deposition inside the parenchymal cells. However, compared with HFD-fed mice, the liver from FTE-treated mice showed scattered fat droplets, suggesting that FTE could promote liver fat metabolism and possibly protect against hepatic steatosis caused by a HFD (Fig. 2E).

The second onset of NAFLD was associated with oxidative stress and lipid peroxidation. ${ }^{41}$ An accumulation of total cholesterol in the liver usually leads to oxidative stress and lipid peroxidation. ${ }^{41} \mathrm{MDA}$ is the final product of lipid peroxidation, and therefore, it has been widely used as an indicator of lipid peroxidation and a marker of oxidative stress, which can be significantly increased after administration of HFD ingestion in both rodents and humans. ${ }^{42}$ Herein, our results showed that hepatic MDA formation in HFD-fed model mice was increased as result of lipid peroxidation (Fig. 3). Interestingly, FTE administration in HFD-fed mice can reduce the generation of MDA in mouse liver. In addition, natural antioxidant enzymes, such as SOD and GSH-Px, can remove lipid peroxidation products and it plays a vital role in the body's defense mechanism against oxidative stress. ${ }^{43}$ As expected, long-term consumption of HFD also reduced SOD and GSH-Px activities, suggesting that chronic HFD consumption weakened the natural antioxidant defense system in mice. However, administration of FTE in HFfed mice inhibited lipid peroxidation, improved antioxidant enzymes system like SOD and GSH-Px activities, and these protective effects might be due to the inhibition of FTE against generation of lipid peroxidation. Moreover, lipid peroxidation stress can promote the formation and release of proinflammatory cytokines. ${ }^{21,44,45}$ In our hands, the levels of IL-1, IL-6, TNF- $\alpha$ and TNF- $\beta$ in the liver of HFD-fed mice were higher than those of normal mice, suggesting that continues 13 weeks of HFD intake caused a severe inflammatory reactions in the liver, maybe leading to liver injury (Fig. 4). However, FTE exerted significant inhibition on the inflammatory reaction in HFD feeding mice. It is also known that AST, ALT and ALP activities are the most powerful biochemical markers for the diagnosis of liver injury. ${ }^{21,46}$ In our study, the long-term HFD intake caused a significant increase in the serum AST, ALT and ALP activities, respectively, and interestingly, administration of FTE significantly decreased the serum AST, ALT and ALP activities in HFDfed mice, proving that it is a good strategy to prevent liver damage caused by HFD (Fig. 4).

The human intestinal microbiota is vital to the health of the host and plays an important role in nutrition, metabolism, pathogen resistance and immune responses. ${ }^{47}$ According to recent reports, the liver, which is the first organ to be exposed to gut-derived toxic factors including bacteria and bacterial products, receives most of blood nutrition supply from the gut through the portal vein, and thus the development of NAFLD may be related to changes in the composition of intestinal microbiota. ${ }^{14,48,49}$ Therefore, we hypothesized that FTE might prevent HFD-induced NAFLD through modulating the gut microbiota and intestinal barrier. ${ }^{50,51}$ It has been reported that NAFLD individuals has lower microbial diversity than individuals without NAFLD. ${ }^{52}$ Herein, the present study showed that the composition of gut microbiota in the HFD-fed mice was altered, which was consistent with previous studies. ${ }^{53}$ Fortunately, our study showed that FTE could enhance the microbial diversity (Fig. 5C). To be specific, we found that Firmicutes were increased, but Bacteroides were decreased in HFD control feeding, leading to intestinal microbiota disorder. ${ }^{7}$ In addition, supplementation with polyphenols and flavonoids was reported to reduce the ratio of Firmicutes to Bacteroidetes, contributing to the prevention of liver injury induced by HFD. ${ }^{54}$ In our study, FTE could significantly reduce the ratio of Firmicutes to Bacteroidetes (Fig. $5 \mathrm{~F}$ ), which is consistent with previous report, ${ }^{55}$ suggesting that the flavonoids rich in FTE was generally poor absorbed with low bioavailability and could reach the large intestine which might be utilized by gut microbiota, ${ }^{56}$ thus contributing to attenuation on the NAFLD induced by HFD. Similarly, the relative abundance of Proteobacteria was significantly reduced after FTE administration when compared with HFD control. Importantly, the massive appearance of Proteobacteria reflected the unstable structures of intestinal microorganisms,${ }^{57}$ which was usually the characteristic of metabolic diseases and intestinal inflammation. ${ }^{58,59}$ At the phylum level, FTE also reduced the relative abundance of Tenericutes in HFDfed mice. At the genus level, it has been reported that Helicobacter often appears in patients with stomach problems. ${ }^{60}$ Herein, our result demonstrated that Helicobacter was sharply increased by HFD feeding in mice (Fig. 6H). In addition, prebiotic consumption has been reported to be associated with an increase of Lactobacillus, ${ }^{61}$ and our results also showed that the intake of FTE significantly increased the relative abundance of Lactobacillus in HFD-fed mice (Fig. 6G), which is consistent with previous report, ${ }^{62}$ suggesting that FTE indeed improved the environment of the gut microbiota. Furthermore, Erysipelatoclostridium, Romboutsia, Corynebacterium, Lactobacillus and Staphylococcus had significant correlation with TC, TG, LDL-C, HDL-C, AST, ALT and ALP, indicating that these gut microbiota might play a central role in amelioration of liver dysfunction by FTE (Fig. 7). All these findings suggest that FTE may alleviate the liver dysfunction by regulating the diversities of intestinal microbiota.

\section{Conclusions}

In summary, this is the first study to show that FTE can improve NAFLD induced by HFD. It was found that FTE could improve the intestinal microbiota imbalance caused by HFD intake in mice. This discovery helps us to understand the mechanism underlying protective effect of drinking Fuzhuan brick tea against the liver damage. This finding opens up the possibility of developing FTE as a new natural ingredient for prevention 
and treatment of intestinal microbiota dysbiosis and liver diseases.

\section{Conflicts of interest}

No potential conflict of interest was reported by the authors.

\section{Acknowledgements}

This study was supported by the National Natural Science Foundation of China (C31671823 and C31871752), the Key Research and Development Plan in Shaanxi Province (2017NY102), the Fundamental Research Funds for the Central Universities of Shaanxi Normal University, China (GK201803074), and the Development Program for Innovative Research Team of Shaanxi Normal University, China (GK201801002). We acknowledge Xi'an Kangfang Food Co., Ltd., China for supply of Jing-Wei Fuzhuan tea materials.

\section{References}

1 S. K. Raatz, L. K. Johnson and M. J. Picklo, J. Nutr., 2015, 145, 2265-2272.

2 L. Tappy and K. A. Le, Physiol. Rev., 2010, 90, 23-46.

3 K. L. Stanhope, V. Medici, A. A. Bremer, V. Lee, H. D. Lam, M. V. Nunez, G. X. Chen, N. L. Keim and P. J. Havel, Am. J. Clin. Nutr., 2015, 101, 1144-1154.

4 R. W. Walker, K. A. Dumke and M. I. Goran, Nutrition, 2014, 30, 928-935.

5 I. Lozano, R. Van der Werf, W. Bietiger, E. Seyfritz, C. Peronet, M. Pinget, N. Jeandidier, E. Maillard, E. Marchioni, S. Sigrist and S. Dal, Nutr. Metab., 2016, 13, 15.

6 J. M. Schwarz, S. M. Noworolski, M. J. Wen, A. Dyachenko, J. L. Prior, M. E. Weinberg, L. A. Herraiz, V. W. Tai, N. Bergeron, T. P. Bersot, M. N. Rao, M. Schambelan and K. Mulligan, J. Clin. Endocrinol. Metab., 2015, 100, 24342442.

7 T. Le Roy, M. Llopis, P. Lepage, A. Bruneau, S. Rabot, C. Bevilacqua, P. Martin, C. Philippe, F. Walker, A. Bado, G. Perlemuter, A. M. Cassard-Doulcier and P. Gerard, Gut, 2013, 62, 1787-1794.

8 S. Greenblum, P. J. Turnbaugh and E. Borenstein, Proc. Natl. Acad. Sci. U. S. A., 2012, 109, 594-599.

9 M. L. Fernandez, Food Funct., 2010, 1, 156-160.

10 Y. L. Wang, A. Q. Xu, P. Liu and Z. J. Li, Nutrients, 2015, 7, 5309-5326.

11 A. Q. Xu, Y. L. Wang, J. Y. Wen, P. Liu, Z. Y. Liu and Z. J. Li, Int. J. Food Microbiol., 2011, 146, 14-22.

12 Q. Cheng, S. Cai, D. Ni, R. Wang, F. Zhou, B. Ji and Y. Chen, J. Food Sci. Technol., 2015, 52, 928-935.

13 Q. Li, Z. Liu, J. Huang, G. Luo, Q. Liang, D. Wang, X. Ye, C. Wu, L. Wang and J. Hu, J. Sci. Food Agric., 2013, 93, 1310-1316.

14 A. C. Keller, T. L. Weir, C. D. Broeckling and E. P. Ryan, Food Res. Int., 2013, 53, 945-949.
15 H. M. Zhang, C. F. Wang, S. M. Shen, G. L. Wang, P. Liu, Z. M. Liu, Y. Y. Wang, S. S. Du, Z. L. Liu and Z. W. Deng, Molecules, 2012, 17, 14037-14045.

16 T. J. Ling, X. C. Wan, W. W. Ling, Z. Z. Zhang, T. Xia, D. X. Li and R. Y. Hou, J. Agric. Food Chem., 2010, 58, 4945.

17 Q. A. Zhang, X. L. Zhang, Y. Y. Yan and X. H. Fan, J. AOAC Int., 2017, 100, 653-660.

18 H. Z. Mo, Y. Zhu and Z. M. Chen, Trends Food Sci. Technol., 2008, 19, 124-130.

19 Z. H. Zhou, H. J. Shao, X. Han, K. J. Wang, C. P. Gong and X. B. Yang, Ind. Crops Prod., 2017, 97, 401-408.

20 H. P. Du, Q. Wang and X. B. Yang, J. Agric. Food Chem., 2019, 67(10), 2839-2847.

21 R. J. Zhang, Y. Zhao, Y. F. Sun, X. S. Lu and X. B. Yang, J. Agric. Food Chem., 2013, 61, 7786-7793.

22 D. Y. Ren, Y. Zhao, Y. Nie, N. N. Yang and X. B. Yang, Int. J. Biol. Macromol., 2014, 69, 296-306.

23 E. Avershina, T. Frisli and K. Rudi, Microbes Environ., 2013, 28, 211-216.

24 B. J. Haas, D. Gevers, A. M. Earl, M. Feldgarden, D. V. Ward, G. Giannoukos, D. Ciulla, D. Tabbaa, S. K. Highlander, E. Sodergren, B. Methe, T. Z. DeSantis, J. F. Petrosino, R. Knight, B. W. Birren and H. M. Consortium, Genome Res., 2011, 21, 494-504.

25 A. Louvet and P. Mathurin, Nat. Rev. Gastroenterol. Hepatol., 2015, 12, 231-242.

26 F. Stickel, S. Buch, K. Lau, H. M. Z. Schwabedissen, T. Berg, M. Ridinger, S. Wiegandt, M. Rietschel, C. Schafmayer, F. Braun, H. Hinrichsen, R. Gunther, A. Arlt, M. Seeger, S. Mueller, H. K. Seitz, M. Soyka, M. Lerch, F. Lammert, C. Sarrazin, R. Kubitz, D. Haussinger, C. Hellerbrand, J. Scholmerich, H. Wittenburg, D. Broring, S. Schreiber, R. Spanagel, K. Mann, M. Krawczak, N. Wodare, H. Volzke and J. Hampe, J. Hepatol., 2010, 52, S459.

27 M. A. Cornier, D. Dabelea, T. L. Hernandez, R. C. Lindstrom, A. J. Steig, N. R. Stob, R. E. Van Pelt, H. Wang and R. H. Eckel, Endocr. Rev., 2008, 29, 777-822.

28 A. Alisi, S. Ceccarelli, N. Panera and V. Nobili, Front. Cell. Infect. Microbiol., 2012, 2(10), 132.

29 Y. Jung, I. Kim, M. Mannaa, J. Kim, S. Wang, I. Park, J. Kim and Y. S. Seo, Food Sci. Biotechnol., 2019, 28, 261-267.

30 X. C. Zhai, D. Y. Ren, Y. Y. Luo, Y. Y. Hu and X. B. Yang, Food Funct., 2017, 8, 2536-2547.

31 W. Li and Y. Lu, J. Food Sci., 2018, 83, 552-558.

32 K. Hu, W. Deng, Y. Zhu, K. Yao, J. Li, A. Liu, X. Ao, L. Zou, K. Zhou, L. He, S. Chen, Y. Yang and S. Liu, MicrobiologyOpen, 2018, e776.

33 M. Afzal, A. M. Safer and M. Menon, Inflammopharmacology, 2015, 23, 151-161.

34 M. Bose, J. D. Lambert, J. Ju, K. R. Reuhl, S. A. Shapses and C. S. Yang, J. Nutr., 2008, 138, 1677-1683.

35 S. Klaus, S. Pultz, C. Thone-Reineke and S. Wolfram, Int. J. Obes., 2005, 29, 615-623.

36 M. Song, D. A. Schuschke, Z. X. Zhou, T. Chen, W. M. Pierce, R. W. Wang, W. T. Johnson and C. J. McClain, J. Hepatol., 2012, 56, 433-440.

37 L. Tappy and K. A. Le, Physiol. Rev., 2010, 90, 23-46. 
38 J. Lai, B. Wu, T. Xuan, S. Xia, Z. Liu and J. Chen, J. Clin. Med. Res., 2015, 7, 446-452.

39 J. M. O. Andrade, A. F. Paraiso, M. V. M. de Oliveira, A. M. E. Martins, J. F. Neto, A. L. S. Guimaraes, A. M. de Paula, M. Qureshi and S. H. S. Santos, Nutrition, 2014, 30, 915-919.

40 Y. Li, H. Ding, J. Dong, S. Ur Rahman, S. Feng, X. Wang, J. Wu, Z. Wang, G. Liu, X. Li and X. Li, J. Cell. Physiol., 2019, 234, 6054-6066.

41 K. Nomura and T. Yamanouchi, J. Nutr. Biochem., 2012, 23, 203-208.

42 M. Singh, A. Kapoor and A. Bhatnagar, Chem.-Biol. Interact., 2015, 234, 261-273.

43 B. B. Fei, L. Ling, C. Hua and S. Y. Ren, Food Chem., 2014, 158, 429-432.

44 W. J. Wang, L. Jiang, Y. M. Ren, M. Y. Shen and J. H. Xie, Int. J. Biol. Macromol., 2019, 124, 788-795.

45 H. C. Zhou, H. Wang, K. Shi, J. M. Li, Y. Zong and R. Du, Molecules, 2018, 24(1), 131.

46 D. Y. Ren, Y. Y. Hu, Y. Y. Luo and X. B. Yang, Food Funct., 2015, 6, 3342-3350.

47 L. Dethlefsen, S. Huse, M. L. Sogin and D. A. Relman, PLoS Biol., 2008, 6, 2383-2400.

48 L. Miele, G. Marrone, C. Lauritano, C. Cefalo, A. Gasbarrini, C. Day and A. Grieco, Curr. Pharm. Des., 2013, 19, 5314-5324.

49 M. E. Dumas, R. H. Barton, A. Toye, O. Cloarec, C. Blancher, A. Rothwell, J. Fearnside, R. Tatoud, V. Blanc, J. C. Lindon, S. C. Mitchell, E. Holmes, M. I. McCarthy, J. Scott, D. Gauguier and J. K. Nicholson, Proc. Natl. Acad. Sci. U. S. A., 2006, 103, 12511-12516.
50 A. Spruss and I. Bergheim, J. Nutr. Biochem., 2009, 20(9), 657662.

51 A. J. Wigg, I. C. Roberts-Thomson, R. B. Dymock, P. J. McCarthy, R. H. Grose and A. G. Cummins, Gut, 2001, 48(2), 206-211.

52 B. Wang, X. Jiang, M. Cao, J. Ge, Q. Bao, L. Tang, Y. Chen and L. Li, Sci. Rep., 2016, 6, 32002.

53 P. D. Cani, A. M. Neyrinck, F. Fava, C. Knauf, R. G. Burcelin, K. M. Tuohy, G. R. Gibson and N. M. Delzenne, Diabetologia, 2007, 50, 2374-2383.

54 I. Moreno-Indias, L. Sanchez-Alcoholado, P. Perez-Martinez, C. Andres-Lacueva, F. Cardona, F. Tinahones and M. I. Queipo-Ortuno, Food Funct., 2016, 7, 1775-1787.

55 G. Chen, M. H. Xie, Z. Q. Dai, P. Wang, H. Ye, X. X. Zeng and Y. Sun, Mol. Nutr. Food Res., 2018, 62(6), 1700485.

56 H. D. Chen and S. M. Sang, J. Funct. Foods, 2014, 7, 26-42.

57 N. R. Shin, T. W. Whon and J. W. Bae, Trends Biotechnol., 2015, 33, 496-503.

58 N. Fei and L. P. Zhao, ISME J., 2013, 7, 880-884.

59 X. C. Morgan, T. L. Tickle, H. Sokol, D. Gevers, K. L. Devaney, D. V. Ward, J. A. Reyes, S. A. Shah, N. LeLeiko, S. B. Snapper, A. Bousvaros, J. Korzenik, B. E. Sands, R. J. Xavier and C. Huttenhower, Genome Biol., 2012, 13, R79.

60 W. Shen, M. Y. Shen, X. Zhao, H. B. Zhu, Y. H. Yang, S. G. Lu, Y. L. Tan, G. Li, M. Li, J. Wang, F. Q. Hu and S. Le, Frontiers in Microbiology, 2017, 8, 272.

61 S. Jangra, R. K. Sharma and R. Pothuraju, Int. Dairy J., 2019, 90, 15-22.

62 M. L. Foster, C. L. Gentile and K. Cox-York, Mol. Nutr. Food Res., 2016, 60(5), 1213-1220. 